\title{
Relationship between papillary thyroid cancer and Hashimoto's disease
}

\section{Papiller tiroid karsinomu ile Hashimoto hastalığı arasındaki ilişki}

\author{
Sema ERDOĞMUŞ ${ }^{1}$, Mümtaz TAKIR², Osman KÖSTEK ${ }^{3}$, Serkan ŞENOL ${ }^{4}$, Hasan Hüseyin MUTLU ${ }^{1}$
}

\begin{abstract}
Thyroid cancer is the most frequent type of endocrine system cancers. Papillary thyroid carcinomas (PTCS) which have favourable prognosis and account for $80 \%$ of thyroid cancer. Hashimoto thyroiditis is the most common cause of hypothroidism in the world. Previous studies demonstrated that chronic inflammation might lead to development of cancer. This paper aimed to determine possible relationship between PTC and Hashimoto's thyroditis. Pathology archives of the patients who had been followed up with the diagnosis of thyroid papillary tumors by clinics of endocrinology, and family medicine, and undergone thyroidectomy between January 2008 and March 2015 were retrospectively reviewed. Patients under 18 years of age were not included in the study the incidence of Hashimoto thyroiditis which accompanied papillary thyroid cancer was retrospectively investigated. PTC and healthy control groups with their pathologic and laboratory data were included in the study. A total of 87 PTC and 87 healthy subjects were enrolled. Of all participants, mean age was $47 \pm 15$ years and male to female ratio was approximately 1:8. in both groups. Family histories regarding thyroid carcinomas, nonthyroidal malignancies, Hashimoto thyroiditis and systematic autoimmune disease revealed similar incidence rates in both groups ( $p>0.05$, for all). Although PTC $p a-$ tients had higher TSH and fT3 median values, while fT4, anti-TPO, anti-Tg values were similar. Finally, association between PTC and Hashimoto thyroiditis was analyzed, and frequency of Hashimoto thyroiditis in PTC patients, and the control group was comparable. The distribution of Hashimoto thyroiditis in patients with PTC was similar to those of the control group.
\end{abstract}

Keywords: Papillary thyroid carcinoma, Hashimoto's thyroiditis, systemic autoimmune diseases
Öz

Tiroid kanserleri en sık görülen endokrin sistem kanserleridir. Papiller tiroid karsinomları, tiroid kanserlerinin yaklaşık \%80'inini oluşturmaktadır ve en iyi prognozlu tipidir. Hashimoto tiroiditi ise dünyada en sık görülen otoimmun tiroidittir ve hipotiroidizmin en sık nedenidir. Daha önce yapılan çalışmalarda, kronik inflamasyonun kansere yol açabileceği gösterilmiştir. Çalışmamızın amacı, papiller tiroid karsinomunu ile Hashimoto tiroiditi arasında bir ilişki varlığını araştırmaktır. Endokrinoloji ve aile hekimliği kliniklerinden Ocak 2008 ve Mart 2015 tarihleri arasında tiroid papiller karsinomu (PTK) nedeniyle takip edilip, patoloji arşivleri incelenerek tiroidektomi yapılan hastalar tarandı. Yaşı 18'in altında olan hastalar çalışmaya dâhil edilmedi. Retrospektif incelemede, papiller tiroid kanserli hastalara eşlik eden Hashimoto tiroiditi sıklığı araştırıldı. Çalışmaya 87 PTK olgusu ve kontrol grubu olarak aynı sayıda 87 kişi dâhil edilmiştir. Hastalarının yaş ortalaması $47 \pm 15$ yıl, erkek/kadın oranı iki grupta da yaklaşık olarak 1:8 idi. Olguların aile öyküsünde tiroid karsinomu, tiroid dışı malignite, Hashimoto tiroiditi ve sistemik otoimmun hastalık açısından iki grup arasında farklılık saptanmadı. Hastaların preop tiroid fonksiyon testleri ve antikor değerleri karşılaştırıldığında, PTC olan hastalarda TSH ve sT3 median değerleri anlamlı olarak yüksek, sT4, anti-TPO, anti-Tg değerleri gruplar arasında anlamlı farklılık yoktu. Papiller tiroid karsinomu ile Hashimoto tiroidit arasındaki ilişki incelendiğinde hastaların hashimoto tiroidit sıklığı kontrol grubu ile benzer olduğu görüldü. Papiller tiroid karsinomlu hastaların Hashimoto tiroiditi dağılımı kontrol grubu ile benzerdi.

Anahtar kelimeler: Papiller tiroid karsinomu, Hashimoto tiroiditi, sistemik otoimmun hastalıklar

sında yer almaktadır. Tiroid hastalıkları klinikte sıklık sırasına göre hipotiroidizm, hipertiroidizm, endemik guatr, tiroidit, ötiroid diffüz guatr ve tiroid kanserleri olmak üzere geniş bir hastalık grubu ile karşımıza gelmektedir ${ }^{1}$.
Tiroid bezinin neden olduğu hastalıklar günümüzde dünyada ve özellikle endemik guatr bölgesi olması nedeniyle ülkemizde çok sık görülen hastalıklar ara-
Received: 16.02 .2016

Accepted: 20.07.2016

${ }^{1}$ Department of Family Medicine

${ }^{2}$ Department of Internal Medicine, Endocrinology And Metabolism Division

${ }^{3}$ Department of Internal Medicine

${ }^{4}$ Department of Pathology, Istanbul Medeniyet University, Gostepe Treaning and Research Hospital

Yazışma adresi: Mümtaz Takır, Istanbul Medeniyet University, Goztepe Training and Research Hospital, Department of Internal Medicine, Endocrinology and Metabolism Division, Istanbul

e-mail: mumtaztakir@yahoo.com 
Endokrin sisteme ait malignitelerin arasında en sık görülen tiroid glanda ait kanserler olmakla birlikte, tüm kanserler içinde tiroid kanseri \%1'den az bir bölümü oluşturur $^{1-3}$. Tiroid kanserleri için bir çok risk faktörü mevcut olmakla birlikte, özellikle yaş, cinsiyet, tiroid bezinde soliter veya dominant bir nodülün varlığı, radyasyona maruziyeti, etnik köken, yetersiz iyot alımı, aile öyküsü, özgeçmişinde tiroid hastalıklarının (kolloidal nodüler guatr, Graves Hastalığı, Hashimoto tiroiditi) olması gibi çeşitli faktörler tiroid kanseri gelişmesinde rol oynayabiliir ${ }^{4,5}$.

Hashimoto tiroiditi ise en sık hipotiroidi nedeni olmakla birlikte kronik lenfositik tiroidit olarak da bilinmekte olup, aynı zamanda en sık otoimmun tiroidit nedenidir. Hashimoto tiroiditinin belirleyici özellikleri, tiroit dokusunda lenfositik infiltrasyon ve lenfoid folikül oluşumudur ${ }^{5}$. Hashimoto tiroiditi ile papiller tiroid kanseri arasında bir ilişki olduğu yapılan birçok çalışmayla gösterilmiş olmasına rağmen, bu iki hastalık arasındaki ilişki kesin olarak kanıtlanamamıştır. Hashimoto tiroiditinde görülen lenfositik infiltrasyon ve immünolojik faktörlerin kronik inflamasyon sonucu papiller tiroid kanserinin oluşumunda rol oynayabileceği düşünülmektedir. Daha önceki çalışmalarda, Hashimoto tiroiditi olan hastaların papiller tiroid kanserine yakalanma şansızlığı normal populasyona oranla üç kat daha sık olduğu görülmüştürr-8.

Çalışmamızdaki amacımız, hastanemizdeki tiroidektomi materyallerinde PTK tanısı alan hastalarda Hashimoto tiroiditi arasındaki ilişkiyi araştırmaktır.

\section{GiRiş ve YÖNTEM}

Çalışma için İstanbul Medeniyet Üniversitesi Göztepe Eğitim ve Araştırma Hastanesinden Etik Kurul onayı (Karar no=2015/0059, Tarih: 04.06.2015) alındıktan sonra, Endokrinoloji ve Aile hekimliği kliniklerinden Ocak 2008 ve Mart 2015 tarihleri arasında tiroid papiller karsinomu nedeniyle takip edilip, tiroidektomi yapılan hastalar tarandı. Papiller tiroid karsinomu (PTK) tanısı alan hastalardaki Hashimoto sıklığı preoperatif tiroit hormon değerleri, otoimmun tiroit antikorları, tiroid ultrosonografi bulguları retrospek- tif değerlendirilerek çalışmaya dâhil edildi. PTK hastaları toplam 87 kişinin dosya verileri geriye yönelik detaylı şekilde incelendi. Hastaların yaşları, cinsiyetleri, operasyon tarihleri, ailede Hashimoto tiroidit, PTK ve diğer kanserlerin bulunup bulunmadığı tespit edildi. Preoperatif dönemde biyokimyasal değerlerin yanında (serum TSH, sT3, sT4, anti Tg, anti TPO) tiroid ultrasonografi verileri çalışmamıza dâhil edildi. Hastalarla iletişim kurularak onam alındıktan sonra özgeçmişlerinde preoperatif Hashimoto tiroiditi ve sistemik otoimmun hastalık varlığı ile soygeçmiş öyküsünde Hashimoto tiroiditi, sistemik otoimmun hastalıklar, tiroid karsinomu ve maligniteleri (tiroid dışı) sorgulandı. Kontrol grubu için dâhil edilme kriteri olarak aile hekimliği polikliniğine başvuran ve bilinen malignite öyküsü olmayan hastalar olarak belirlendi. Poliklinik sıra numarası 5 ve katları olacak şekilde randomize edildi. Hastalardan biyokimyasal ve ultrasonografik işlemleri sonrasında 87 kontrol hastası dâhil edildi.

\section{İstatistiksel İnceleme:}

SPSS 16.0 for windows programı kullanılarak, kategorik verilerin analizi ki-kare testi ile yapıldı. Sayısal verilerin analizinde Kolmogorov-Smirnov testi ile normal dağılıp dağılmadığı incelendi. Normal dağılım gösteren veriler arasında analiz one way-ANOVA testi ile analiz edildi. Normal dağılım göstermeyen veriler ise non-parametrik test karşılığı olan Kruskal-Wallis testi ile değerlendirildi. İkili gruplar arasında sayısal veriler ise normal dağılım gösteriyorsa student $t$ testi, normal dağılım göstermiyorsa non-parametrik karşılığı olan Mann Whitney U testi ile değerlendirildi. $p<0,05$ değeri istatiksel olarak anlamlı kabul edildi.

\section{BULGULAR}

Çalışmaya Ocak 2008 - Mart 2015 tarihleri arasında toplam 87 papiller tiroid kanser olgusu ve kontrol grubu olarak aynı sayıda 87 kişi dâhil edilmiştir. PTK tanılı hastaların yaşları 18 ile 78 arasında olup, ortalama yaş $47 \pm 15$ yıl idi, bunların 10'u (\%11,5) erkek, 77 'si $(\% 88,5)$ kadındı. Kontrol grubunun ise yaşları 18 ile 80 arası değişmekteydi, yaş ortalaması $47 \pm 15$ yıl olup, bunların 21'i $(\% 24,1)$ erkek, 66'sı $(\% 75,9)$ 
kadınlardan oluşmaktaydı. Olguların aile öyküsünde tiroid karsinomu varlığı, PTK olgularından $3(\% 3,4)$ kişi, kontrol grubundan ise $2(\% 2,3)$ kişide mevcuttu. Tiroid dışında malignite varlığı ise PTK olgularında 22 $(\% 25,3)$ kişi, kontrol grubunda ise $43(\% 49,4)$ kişide soygeçmişinde saptanmıştı. Aile öyküsünde Hashimoto tiroiditi varlığı, PTK olgularında $22(\% 25,3)$ kişide, kontrol grubunda ise $35(\% 40,2)$ kişide mevcutken; sistemik otoimmun hastalığı ise PTK olgularında $4(\% 4,6)$ kişi, kontrol grubunda ise $5(\% 5,7)$ kişide mevcuttu (Tablo 1).

Tablo 1. Hastaların demogrofik özellikleri ve soygeçmişleri.

\begin{tabular}{|c|c|c|c|}
\hline & $\begin{array}{l}\text { PTK grubu } \\
(n=87)\end{array}$ & $\begin{array}{l}\text { Kontrol grubu } \\
(n=87)\end{array}$ & $\stackrel{p}{\text { değeri }}$ \\
\hline Yaş (yıl), Ort.土SD & $47 \pm 15$ & $47 \pm 15$ & 0,81 \\
\hline \multicolumn{4}{|l|}{ Cinsiyet, n (\%) } \\
\hline Kadın & $77(88,5)$ & $66(75,9)$ & 0,02 \\
\hline Erkek & $10(11,5)$ & $21(24,1)$ & \\
\hline \multicolumn{4}{|l|}{ Aile öyküsü, n (\%) } \\
\hline Tiroid kanser varlığı & $3(3,4)$ & $2(2,3)$ & 0,32 \\
\hline Hashimoto varlığı & $22(25,3)$ & $35(40,2)$ & 0,23 \\
\hline $\begin{array}{l}\text { Sistemik otoimmun hastalık } \\
\text { varlığı }\end{array}$ & $4(4,6)$ & $5(5,7)$ & 0,12 \\
\hline Malignite varlığı (tiroid dışı) & $22(25,3)$ & $43(49,4)$ & 0,75 \\
\hline
\end{tabular}

Hastaların preoperatif tiroid fonksiyon testleri ve antikor değerleri karşılaştırıldığnda, PTK olan hastalarda TSH ortanca değeri 1,3 ulU/ml (çeyreklerarası mesafe $0,7-2,3 \mathrm{ulU} / \mathrm{ml}$ ), kontrol grubunda ise median değeri 1,6 ulU/ml (çeyreklerarası mesafe 1,1-2,8 ulU/ml) olup anlamlı farklılık saptanmıştı $(p=0,01)$. Serbest T4, PTK grubunda ortanca değeri $0,8 \mathrm{ng} / \mathrm{dl}$ (çeyreklerarası mesafe $0,7-1,1 \mathrm{ng} / \mathrm{dl})$, kontrol grubunda ise ortanca değeri 0,9 ng/dl (çeyreklerarası mesafe 0,8$1,1 \mathrm{ng} / \mathrm{dl}$ ) olup, gruplar arasında anlamlı bir farklılık saptanmamıştı $(p=0,09)$. Serbest T3, PTK grubunda ortanca değeri $3,1 \mathrm{pg} / \mathrm{ml}$ (çeyreklerarası mesafe $2,8-3,4 \mathrm{pg} / \mathrm{ml})$, kontrol grubunda ise ortanca değeri $2,7 \mathrm{pg} / \mathrm{ml}$ (çeyreklerarası mesafe 2,5-3,1 pg/ml) saptanmış olup, gruplar arası anlamlı farklılık mevcuttu $(<0,001)$. Serum antikor düzeyleri incelendiğinde PTK grubunda sırasıyla, anti-TPO ortanca değeri 1,5 IU/ $\mathrm{ml}$ (çeyreklerarası mesafe 0,4-3,23 IU/ml), anti $\mathrm{Tg}$ ortanca değeri 9,4 IU/ml (çeyreklerarası mesafe 0,9$25,8 \mathrm{IU} / \mathrm{ml}$ ); kontrol grubunda ise anti-TPO ortanca değeri 0,6 IU/ml (çeyreklerarası mesafe 0,5-25,3 IU/ $\mathrm{ml}$ ), anti Tg ortanca değeri 2,1 IU/ml (çeyreklerarası mesafe 1,4-25,8 IU/ml) olup, gruplar arasında anlamlı farklıık saptanmamıştı (anti TPO $p=0,99$, anti Tg $p=0,88$ ) (Tablo 2).

Tablo 2. Hastaların laboratuvar değerleri.

\begin{tabular}{|c|c|c|c|}
\hline & $\begin{array}{l}\text { PTK grubu } \\
(n=87)\end{array}$ & $\begin{array}{l}\text { Kontrol grubu } \\
(n=87)\end{array}$ & $\stackrel{p}{\text { değeri }}$ \\
\hline \multicolumn{4}{|l|}{ TSH (ulU/ml) } \\
\hline Ortanca & 1,3 & 1,6 & 0,01 \\
\hline $\begin{array}{l}\text { Çeyrekler arası mesafe } \\
\text { Serbest T4 (ng/dl) }\end{array}$ & $0,7-2,3$ & $1,1-2,8$ & \\
\hline Ortanca & 0,8 & 0,9 & 0,09 \\
\hline $\begin{array}{l}\text { Çeyrekler arası mesafe } \\
\text { Serbest T3 }(\mathrm{pg} / \mathrm{ml})\end{array}$ & $0,7-1,1$ & $0,8-1,1$ & \\
\hline Ortanca & 3,1 & 2,7 & $<0,001$ \\
\hline $\begin{array}{l}\text { Çeyrekler arası mesafe } \\
\text { Anti-TPO }(\mathrm{IU} / \mathrm{ml})\end{array}$ & $2,8-3,4$ & $2,5-3,1$ & \\
\hline Ortanca & 1,5 & 0,6 & 0,99 \\
\hline $\begin{array}{l}\text { Çeyrekler arası mesafe } \\
\text { Anti-Tiroglobulin (IU/ml) }\end{array}$ & $0,4-3,23$ & $0,5-25,3$ & \\
\hline Ortanca & 9,4 & 2,1 & 0,88 \\
\hline Çeyrekler arası mesafe & $0,9-25,8$ & $1,4-25,8$ & \\
\hline
\end{tabular}

Hastaların tiroid ultrasonografi raporları incelendiğinde PTC ile kontrol grupları arasında tiroid bezinin hiperplazisi PTC grubunda 42 (\%48,3) kişide, kontrol grubunda ise $14(\% 16,1)$ kişide ve gruplar arası anlamlı farklılık mevcuttu $(p<0,001)$. Heterojenitesi incelendiğinde PTC grubunda 60 (\%69) kişide, kontrol hastalarında $30(\% 34,5)$ kişide mevcut olup, gruplar arası anlamlı farklılık mevcuttu $(p<0,001)$. Tiroid bezinin ekojenitesi değerlendirildiğinde, PTC grubunda hipoekojenite $39(\% 44,8)$ kişide, izoekojenite 39 $(\% 44,8)$ kişide, hiperekojenite $5(\% 5,7)$ kişide, kontrol grubunda ise hipoekojenite $17(\% 19,5)$ kişide, izoekojenite 67 (\%77) kişide, hiperekojenite $3(\% 3,4)$ kişide izlenmişti. Kalsifikasyon durumu karşılaştırıldığında PTC hastalarında $41(\% 47,1)$ kişide, kontrol grubunda ise $2(\% 2,3)$ kişide görülmüş olup, anlamlı bir farklılık saptanmıştı $(p<0,001)$. Kistik nodul varlığı ise PTC grubunda $33(\% 37,9)$ kişide, kontrol grubunda $6(\% 6,9)$ kişide saptanmıştı, gruplar arasında anlamlı bir farklılık mevcuttu $(p<0,001)$.

Olguların nodul varlığı ve özellikleri karşılaştırıldığında, PTC grubunda toplam 82 (\%94,3) kişide nodul izlenmiş olup bunların 21 'inde $(\% 24,1)$ yalnızca sağ 
lobda, $18^{\prime}$ inde $(\% 20,7)$ yalnızca sol lobda, 43'ünde $(\% 49,4)$ ise bilateral yerleşimliydi. Sağ lob nodul boyutları ortalama $21,9 \pm 15,7 \mathrm{~mm}$ olup, sağ lobdaki dominant nodul olan kişi sayısı $48(\% 55,2)$ iken, sol lob nodul boyutları ortalama $19,3 \pm 15,4 \mathrm{~mm}$ olup sol lobdaki nodulun dominant olduğu kişi sayısı 34 $(\% 39,1)^{\prime}$ tür. Kontrol grubunda toplam $16(\% 18,4)$ kişide nodul izlendi. Yalnızca $6(\% 6,9)$ kişide sağ lobda, $5(\% 5,7)$ kişide yalnızca sol lobda, $5(\% 5,7)$ kişide ise bilateral yerleşimliydi. Sağ lob nodul boyutları ortalama 10,4 $\pm 7,4 \mathrm{~mm}$ olup, sağ lobdaki nodulun dominant olduğu kişi sayısı ise $9(\% 10,3)$ 'du. Sol lob nodul boyutları ortalama $9,6 \pm 6,3 \mathrm{~mm}$ olup, sol lobdaki nodulun dominant olduğu kişi sayısı 7 (\%8) kişiydi. PTC grubu ile kontrol grubu arasında nodul varlığı açısından, sol lob ve sağ lob nodul boyutları arasında

Tablo 3. Hastaların USG sonuçları.

\begin{tabular}{|c|c|c|c|}
\hline & $\begin{array}{l}\text { PTK grubu } \\
(n=87)\end{array}$ & $\begin{array}{l}\text { Kontrol grubu } \\
(n=87)\end{array}$ & $\stackrel{p}{\text { değeri }}$ \\
\hline Hiperplazi & $42(48,3)$ & $14(16,1)$ & $<0,001$ \\
\hline Heterojenite & $60(69)$ & $30(34,5)$ & $<0,001$ \\
\hline \multicolumn{4}{|l|}{ Ekojenite } \\
\hline Hipoekoik & $39(44,8)$ & $17(19,5)$ & \\
\hline İzoekoik & $39(44,8)$ & $67(77)$ & $<0,001$ \\
\hline Hiperekoik & $5(5,7)$ & $3(3,4)$ & \\
\hline Kalsifikasyon & $41(47,1)$ & $2(3,4)$ & $<0,001$ \\
\hline Kistik & $33(37,9)$ & $6(6,9)$ & $<0,001$ \\
\hline Nodul varlığı & $82(94,3)$ & $16(18,4)$ & $<0,001$ \\
\hline Sağ nodul dominant & $48(55,2)$ & $9(10,3)$ & \\
\hline Sol nodul dominant & $34(42,5)$ & $7(8)$ & 0,86 \\
\hline $\begin{array}{l}\text { Nodul boyut } \\
\text { Sağ (mm) }\end{array}$ & $21,9 \pm 15,7$ & $10,4 \pm 7,4$ & 0,02 \\
\hline Sol (mm) & $19,3 \pm 15,4$ & $9,6 \pm 6,3$ & 0,002 \\
\hline \multicolumn{4}{|l|}{ Nodul yerleşim } \\
\hline Sağ nodul & $21(24,1)$ & $6(6,9)$ & \\
\hline Sol nodul & $18(20,7)$ & $5(5,7)$ & 0,15 \\
\hline Bilateral & $43(49,4)$ & $5(5,7)$ & \\
\hline
\end{tabular}

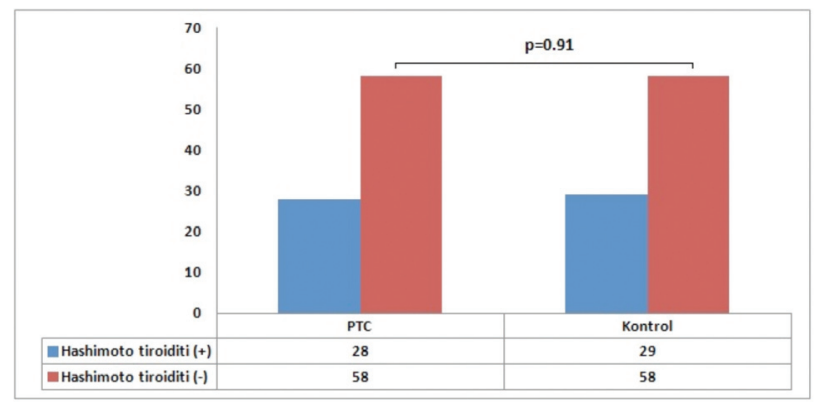

Figür 1. Papiller tiroid karsinomu ile Hashimoto tiroidit ilişkisi. anlamlı bir farklılık mevcutken $(p<0,001, p=0,002$ ve $p=0,02$ sırasıyla), nodullerin yerleşimi ve dominant nodul lokalizasyonları arasında anlamlı bir farklılık saptanmamıştır ( $p=0,15, p=0,86$,) (Tablo 3). Papiller tiroid karsinomu ile Hashimoto tiroidit arasındaki ilişki incelendiğinde hastaların hashimoto tiroidit sıklığı kontrol grubu ile benzer olduğu görüldü (Figür 1).

PTC olgularında sistemik otoimmün hastalıkların (Sjögren sendromu, SLE, sarkoidoz, otoimmun poliglandüler sendrom, sistemik sklerozis, psöriatik artrit, kriyoglobulinemi) varlığı incelendiğinde, yalnızca 1 hastada otoimmun poliglandüler sendrom (OPS) olduğu görüldü. Kontrol grubunda ise 3 kişide SLE, 3 kişide psöriatik artrit, 1 kişide sjöngren sendromu, 1 kişide OPS ve 1 kişide de sistemik sklerozis tanısı mevcutken kriyoglobulinemi tanısına rastlanmadı.

\section{TARTIŞMA}

Tiroid maligniteleri endokrin sisteme ait en sık görülen kanser grubu olup, düşük riskli hastalarda ölüm oranı düşüktür. PTK differansiye tiroid malignitelerinin en sık ve en iyi prognozlu tipidir. Prognozu belirlemek için kullanılan faktörler ise ileri yaş, metastaz varlığı, hastalığın yaygınlığı, cinsiyet, tümör çapı ve gradedir ${ }^{9}$. Hashimoto tiroiditinde meydana gelen kronik inflamasyonun papiller tiroid karsinomuna sebep olabileceği öne sürülmüş olup, daha önce yapıIan çalışmalarda Hashimoto tiroiditi olan hastalarda PTK sıklığının arttığı gözlenmiştir ${ }^{10}$. Çalışmamızda ise, PTK tanısı alan hastalarda Hashimoto tiroiditi varlığı kontrol gurubu ile benzer sıklıkta olduğu görüldü.

PTK etyopatogenezinde tiroid bezi fonksiyon bozukluğunda, devamlı ve süregelen TSH uyarısı sonucunda tiroid bezinde düzensiz büyüme ortaya çıkmaktadır ${ }^{11}$. Iyot eksikliği, tiroid bezinin hormon üretmeindeki yetersizliği, dışarıdan (diyet veya ilaç vb.) alınan guatrojenler de TSH uyarısına neden olarak tiroid kanseri riskinde artışa yol açmaktadır. Preklinik çalışmalarda da uzun süren iyot eksikliği ile beslenen hayvanlarda, başlangıçta folliüler hiperplazi gelişimini sırasıyla nodül ve adenom oluşumu izlemiştir ${ }^{12}$. Endemik guatr bölgelerinde folliküler tiroid karsinomu PTK'dan 
daha sık görülmekle beraber, eğer iyot profilaksisi uygulanırsa bu ilişki tersine dönmektedir ${ }^{13}$. PTK olgularımızda TSH ve serbest T4 değerleri daha düşük izlenmiş, serbest T3 değeri ise kontrol grubuna göre daha yüksekti ( $p=0,01, p=0,09$ ve $p<0,001$, sırasıyla). Bulgularımızda TSH, serbest T3 ve T4 değerleri normal referans aralıklarında idi.

Preoperatif dönemde cerrahi hastaları elektif cerrahi şartlarında ötiroid olmalarına özen gösterilmelidir. Aksi durumda intraoperatif hipotansiyon, myokard kontraktilitesinde azalma ve kalp yetmezliği, gastrik hipomobilite gibi komplikasyonlar görülebilir. Acil cerrahi durumlarında, hastanın ötiroidiz hâle gelmesi beklenemeyecekse bu durumda 5-7 günlük kısa süreli T4 replasmanıyla da risk azaltılabilir. Subklinik hipotiroidizmde ise acil veya elektif cerrahi durumlarında bakılan TSH değeri $<10 \mu \mathrm{IU} / \mathrm{mL}$ iken T4 replasman gereği yoktur. Eğer TSH değeri $>10 \mu \mathrm{IU} / \mathrm{mL}$ ise T4 replasmanı başlanılarak TSH değerinin $<10 \mu \mathrm{IU} /$ $\mathrm{mL}$ düşmesi beklenilmelidir ${ }^{1,2}$.

PTK'lı hastaların TSH değerlerinin yüksek seyretmemiş olması preoperatif dönemde TSH uyarısının neden olabileceği trofik etki riskinin olmadığını düşündürmüştür. Oto-antikorları yüksek olanlarda tiroidin papiller kanseri daha sık görülmektedir ${ }^{12}$. Anti-TPO ve anti-tiroglobulin değerlerinin gruplar arasında benzer oldukları görüldü ( $p=0,99$ ve $p=0,088$, sırasıyla). Çalışmamızda, PTK ile Hashimoto tiroiditi ve diğer sistemik otoimmun hastalıkları arasında ilişkinin saptanmamıs olması otoimmun antikorların gruplar arasındaki benzerliği açıklamaktaydı.

Tiroid nodüllerinin neoplazik oluşumlarında görülen hipoekojenite, kalsifikasyon, periferal halonun bulunmayışı ve düzensiz sınırlar gibi USG bulguları önemlidir ${ }^{14}$. Bu bulguların birden fazlasının bulunmasının tanısal doğruluk oranını arttırdığı bazı çaIışmalarda bildirilmektedir ${ }^{15,16}$. Diğer taraftan Çiriş ve ark. ${ }^{17}$ ultrasonografik çalışmaların biyopsi kanıtlı malign nodülleri tespit etmede yetersiz kalabileceğini ve kesin ultrasonografik kriterlerin tam anlamda olduğunu söyleyebilmenin yetersiz olduğunu belirtmişlerdir. Çalışmamız tiroid papiller karsinom olgularında ultrasonografik anormalliklerin (sırasıyla hiperplazi $p<0,001$, heterojenite $p<0,001$, hipoekojenite $p<0,001$, kalsifikasyon $p<0,001$, kistik oluşum $p<0,001$ ve nodul varlığı $p<0,001$ ) daha fazla olduğu görüldü. Biyopsi açısından öncelikler tanıya ulaşmada öngörülen dominant nodül yerleşim yeri daha çok sağ tarafta izlenmiş olsa da yerleşim yerleri gruplar arasında istatiksel açısıdan benzerdi $(p=0,86)$.

Hashimoto tiroiditi ile diferansiye tiroid kanserleri arasında herhangi bir ilişkinin olup olmadığı çeşitli klinikler tarafından irdelenmiş, özellikle PTK ile Hashimoto tiroiditi arasında ilişkinin varlığı bazı çalışmalarda iddia edilmiştir. Patogenezde özellikle Hashimoto tiroiditi ve PTK arasında ortak hücre içi sinyal aktarım proteinleri arasında ilişki gösterilmeye çalışımıştır ${ }^{18}$. Özellikle bu mekanizmalardan biri olan fosfotidil inositol-3 kinaz (PI3K) hücrenin yaşam ve programIı ölüm arasındaki dengede kritik bir rol oynar, ${ }^{5,19-21}$. Ott ve ark., ${ }^{6}$ tiroid kanserli 161 hastada Hashimoto ve PTK birlikteliğini \%38 olarak bildirmişlerdir. Singh ve ark., ${ }^{7}$ PTK'li 388 hastada, Hashimoto birlikteliğini \%15 olarak ortaya koymuşlardır. Cipolla ve ark. ${ }^{8}$ ise PTK'li 89 hastada Hashimoto insidansını \%27 olduğunu göstermişlerdir. Hashimoto tiroiditi ve papiller tiroid karsinomu arasında ilişkinin gözlenmediğine en kapsamlı çalışma Jankovic ${ }^{10}$ tarafından yapılan derlemede belirtilmiştir. Özellikle PTK ve Hashimoto arasındaki ilişkiyi savunan çalışmalarda patolojik spesmenlerdeki her lenfosittik infiltrasyonun Hashimoto olarak belirtilmesinin önemli bias oluşturduğu gözlenmiştir. Tümöral oluşum çevresindeki fokal lenfosittik infiltrasyonun Hashimoto tiroiditi ile birlikteliği olarak raporlanması, diffüz lenfosittik infiltrasyon olarak bilinen Hashimoto tiroiditi için yanlış pozitiflik ilişkiye neden olacağını düşündürmektedir.

Sonuç olarak, çalışmamızda papiller tiroid karsinomlu hastaların Hashimoto tiroiditi dağılımı kontrol grubu ile benzer olduğu görülmüş $(p=0,91)$. Hashimoto tiroiditi ile PTK arasındaki ilişkinin ispatlanması için geniş popülasyonlu randomize kontrollü prospektif daha fazla çalışmalara gereksinim duyulmaktadır. 


\section{KAYNAKLAR}

1. Tiroid Hastalıklari Tanı ve Tedavi Kılavuzu. Türkiye Endokrinoloji ve Metabolizma Derneği 2015.

2. Mark HB, Robert B. Thyroid disorders.In The Merck Manual, $17^{\text {th }}$ ed. Edit. Mark HB, Robert B. Merck Research Laboratories. NJ, 1999; p:81-100.

3. DeLellis RA, Williams ED. Thyroid and parathyroid tumors; introduction. InTumors of Endocrine Organs, World Health Organization Classification of Tumors. Edit. Ronald ADL, Ricardo VL, Phillip UH, Charis E. 2004; $1^{\text {st }}$ ed., Lyon, p:51.

4. Naweed R, Manish D, Phill M., et al. Risk factors for well differentiated thyroid carcinoma in patients with thyroid nodular disease. Otolaryngology-Head and Neck Surgery 2008;139:21-6.

http://dx.doi.org/10.1016/j.otohns.2007.10.021

5. Shawn DL, Lindsey NJ, Taylor SR, et al: Increased incidence of well differentiated thyroid cancer associated with Hashimoto thyroiditis and the role of PI3K/Akt Pathway . J Am Coll Surg 2007;204:764-75. http://dx.doi.org/10.1016/j.jamcollsurg.2006.12.037

6. Jeong SH, Hong HS, Lee H, et al. Papillary Thyroid Carcinoma Arising in Children and Adolescent Hashimoto's Thyroiditis: Ultrasonographic and Pathologic Findings. International Journal of Endocrinology 2016. http://dx.doi.org/10.1155/2016/2397690

7. Singh B, Shaha AR, Triverdi H, et al. Coexistent Hashimoto's thyroiditis with papillary thyroid carcinoma: Impact on presentation. Management and Outcome Surgery 1999;126:1070-7. http://dx.doi.org/10.1067/msy.2099.101431

8. Cipolla C, Sandonato L, Graceffa G, et al. Hashimoto thyroiditis coexistent with papillary thyroid carcinoma. Am Surg 2005;71:874-8.

9. Başoğlu M, Karabulut K. İyi diferansiye tiroit kanserleri. Journal of Experimental and Clinical Medicine Deneysel ve Klinik Tıp Dergisi.

10. Bojana Jankovic, Karen T. Le, Jerome M. Hershman. Hashimoto's Thyroiditis and Papillary Thyroid Carcinoma: Is There a Corre- lation?. J Clin Endocrinol Metab 2013;98(2):474-82. http://dx.doi.org/10.1210/jc.2012-2978

11. Tonbul AT. Kliniğimizde tedavi ve takip edilen 500 diferansiye tiroid karsinomlu olgu örnekleminde demografik özellikler. İstanbul Okmeydanı Eğitim ve Araştırma Hastanesi Nükleer Tıp Kliniği, Uzmanlık Tezi İstanbul 2008.

12. Collins SL. Thyroid cancer: controversies and ethiopathogenesis. In thyroid disease: second edition: Falk SE. Lippincot Raven. Philadelphia 1997;11:495-564.

13. Mintziori G, Adamidou F, Kita M, et al. Hashimoto's thyroiditis and papillary thyroid cancer: polyglandular hints. Trends in Endocrinology \& Metabolism 2015; 26.8: 395.

14. Yüksekkaya ZR, Çelikyay F, and Bağcı P. Benign ve malign tiroid nodüllerinde ultrasonografi bulguları. Fırat Üniversitesi Sağ Bil Tıp Der 2011;25:77-82.

15. Papini E, Guglielmi R, Bianchini A, et al. Risk of malignancy in nonpalpable thyroid nodules: predictive value of ultrasound and color Doppler features. J Clin Endocrinol Metab 2002;87:1941-1946. http://dx.doi.org/10.1210/jcem.87.5.8504

16. Hegedus L. Thyroid ultrasound. Endocrinol Metab Clin North Am 2001;30:339-360. http://dx.doi.org/10.1016/S0889-8529(05)70190-0

17. Çiriş $F$, Gümüş $H$, Gümüş $M$, et al. Nodüler tiroid hastalıklarında ultrasonography, sintigrafi ve ince iğne aspirasyon biopsisis (iiAB) sonuçlarının karşılaştırılması. AÜTD 2002;43:87-91.

18. Jackson L, Evres BM. Chronic inflammation and pathogenesis of GI and pancreatic cancers. Cancer Treat Res 2006;130:3965.

http://dx.doi.org/10.1007/0-387-26283-0_2

19. Blume Jensen $P$, Hunter T. Oncogenic kinase signalling. Nature 2001;411:355-65. http://dx.doi.org/10.1038/35077225

20. Miyakawa M, Tsushima T, Murakami H, et al. Increased expression of phosphorylated p70S6 kinase and Akt in papillary thyroid cancer tissues. Endocr J 2003;50:77-83. http://dx.doi.org/10.1507/endocrj.50.77

21. Cipolla C, Sandonato L, Graceffa C, et al. Hashimoto thyroiditis coexistent with papillary thyroid carcinoma. Am Surg 2005;71:874-8. 